\title{
Desenvolvimento pré-imaginal de Eueides isabella dianasa (Hübner) (Lepidoptera, Nymphalidae, Heliconiinae) em folhas de Passiflora edulis L. (Passifloraceae) $)^{1}$
}

\author{
Wagner Ricardo Santos Barros ${ }^{1} \&$ Iracilda Maria de Moura Lima²
}

\begin{abstract}
${ }_{2}^{1}$ Trabalho de Conclusão do primeiro autor no Curso de Graduação em Ciências Biológicas, Universidade Federal de Alagoas.
2Pós-graduando em Agronomia, Departamento de Fitotecnia e Fitossanidade, Universidade Federal de Alagoas. Campus Delza Gitaí, BR 104 Norte, Km 85, 57100-000 Rio Largo-AL, Brasil. Endereço eletrônico: wsantosbarros@ibest.com.br.

${ }^{3}$ Departamento de Zoologia, Universidade Federal de Alagoas. Praça Afrânio Jorge s/n, Prado, 57010-020 Maceió-AL, Brasil.
\end{abstract}

\begin{abstract}
Preimaginal development of Eueides isabella dianasa (Hübner) (Lepidoptera, Nymphalidae, Heliconiinae) on leaves of Passiflora edulis L. (Passifloraceae). The preimaginal development of Eueides isabella dianasa (Hübner, 1806) feeding on leaves of P.edulis was studied under laboratory conditions. The eggs were collected soon after oviposition. Eclosion, and ecdisys (confirmed by the cephalic capsules), pupation and adult emergence were registered daily. The egg viability was $94.9 \%$. The embryonic period (in days \pm average standard error) was $4.25 \pm 0.18$. The $16.9 \pm 0.34$ larval period has five instars: $2.75 \pm 0.2 ; 2.8 \pm 0.2 ; 3.0 \pm 0.1 ; 3.6 \pm 0.2$ and $4.6 \pm 0.15$. The active larval period was $15.83 \pm$ 0.34 , followed by an one day prepupal period and a pupal instar of $7.42 \pm 0.15(8.4 \pm 0.15$ inactive period of the postembryonic development). The post-embryonic development was $24.25 \pm 0.37$. The total pre-imaginal period was 28.5 \pm 0.44 long and may be considered short. The relative duration was $14.9 \%$ for the embryonic period and $85.9 \%$ for the post-embryonic. The use of the time in the post-embryonic development was $11.3 \%, 11.7 \%, 12.4 \%, 14.8 \%, 18.9 \%$, $30.6 \%$ respectively for L1, L2, L3, L4, L5 and pupa. The larval period represented $65.3 \%$ while the inative (prepupa + pupa) $34.7 \%$. The survival at the end of the development, considering the egg period, was $27.5 \%$ and considering the post-embryonic period, $30,0 \%$. It was more evident on the $5^{\text {th }}$ instar and at the pupal period, with $63.0 \%$ and $64.7 \%$, respectively. This is the first record of Eueides isabella dianasa for the State of Alagoas, Brazil.
\end{abstract}

KeYwords. Eueides isabella dianasa; life cycle; new record; relative duration; survival.

Resumo. Lagartas de Eueides isabella dianasa (Hübner, 1806) estão entre os insetos fitófagos que ocorrem em P. edulis. Para esse estudo, foram coletados ovos logo após a oviposição, sendo feitas observações diárias para o registro de eclosão, ecdises (confirmadas pelas cápsulas cefálicas), pupação e emergência de adultos. A viabilidade de ovos foi de $94,9 \%$. O período embrionário observado (em dias \pm erro padrão da média) foi de $4,25 \pm 0,18$. O período larval de 16,9 \pm 0.34 dias apresentou cinco ínstares: $2,75 \pm 0,2 ; 2,8 \pm 0,2 ; 3,0 \pm 0,1 ; 3,6 \pm 0,2$ e 4,6 $\pm 0,15$. O período larval ativo foi de 15,83 \pm 0,34 dias, seguido por um período prepupal e pupal de, respectivamente, de 7,42 $\pm 0,15$ (período inativo dentro do desenvolvimento pós-embrionário de 8,4 $\pm 0,15$ ). O desenvolvimento pós-embrionário foi de $24,25 \pm 0,37$. A duração do desenvolvimento pré-imaginal de $28,5 \pm 0,4$ pode ser considerada curta entre os lepidópteros. A duração relativa foi de $14,9 \%$ para o período embrionário e de $85,9 \%$ para o pós-embironário. O uso do tempo durante o período pós-embrionário foi de $11,3 \% ; 11,7 \% ; 12,4 \% ; 14,8 \% ; 18,9 \%$ e 30,6\% respectivamente como L1, L2, L3, L4, L5 e pupa. O período larval representou $65,3 \%$ enquanto o período inativo (prepupa + pupa) $34,7 \%$. A sobrevivência no final do desenvolvimento, considerando o período de ovo, foi de $27,5 \%$ e, considerando o período pós-embrionário, 30,0\%, tendo sido mais evidente no quinto ínstar e no período pupal com $63,0 \%$ e $64,7 \%$, respectivamente. Este é o primeiro registro de Eueides isabella dianasa no Estado de Alagoas, Brasil.

Palavras-Chave. Ciclo de vida; duração relativa; Eueides isabella dianasa; novo registro; sobrevivência.

Muitas espécies de lepidópteros apresentam um traço característico que é o de suas lagartas se alimentarem de uma determinada espécie de vegetal, muitas vezes única e exclusivamente. Esse fenômeno é conhecido como oligofagia e é comum entre representantes da subfamília Heliconiinae (Lepidoptera, Nymphalidae) (CARRERA 1989).

Entre os insetos fitófagos oligófagos a escolha da planta hospedeira para as larvas está indiretamente determinada pela seleção do sítio para oviposição, onde as escolhas se baseiam não só nos atributos interespecíficos dessas plantas, mas também na variação entre as plantas de uma mesma espécie (Mugrabi-Oliveira \& Moreira 1996).

Essa relação estreita de dependência é um indicativo de que houve coevolução entre os dois grupos (FIGUEIREDO 2000). Os representantes da subfamília Heliconiinae têm sua ocorrência registrada em muitas espécies de Passifloraceae (Silva et al.1968; CARRERA 1984), principalmente, Passiflora edulis L. (OTERO 1986).

Os estágios imaturos de 14 espécies de heliconiíneos, incluindo Eueides isabella isabella (Cramer, 1871 ), foram descritos e ilustrados por BEEBE et al. (1960). A morfologia externa dos estágios imaturos de Eueides isabella dianasa (Hübner, 1806) foi descrita por ANTUNEs et al. (2002).

$\mathrm{Na}$ área urbana de Maceió ocorrem diversas espécies de borboletas entre as quais $E$. isabella dianasa, cujos adultos (Fig. 2) são abundantes entre os meses de setembro e 
novembro.

O‘ToOle (1995) e BeEBE et al. (1960) registraram a ocorrência de E. isabella em Trinidad. HolzINGER \& HolzINGER (1994) apud ANTunes et al. (2002), citaram a ocorrência de E. isabella dianasa, no Brasil, desde Santa Catarina até a Bahia, e também no Pará, não fazendo referência à área entre estes dois estados. No entanto, Lima \& Veiga (1993) apresentaram registro para Pernambuco.

PICANÇO et al. (2001) relacionaram-na entre as lagartas desfolhadoras em plantios comerciais de maracujá, mas sem considerá-la praga.

O conhecimento da ocorrência de oviposição de E. isabella dianasa em folhas de $P$. edulis (maracujazeiro) possibilitou o estudo do desenvolvimento pré-imaginal em laboratório, tornando possível que os seguintes objetivos fossem atingidos: 1) estabelecimento da duração, em dias, de cada uma das fases do desenvolvimento pré-imaginal; 2) estabelecimento da duração relativa dos estádios do desenvolvimento préimaginal; 3) determinação da viabilidade dos ovos; 4) determinação da percentagem de sobrevivência durante o desenvolvimento pós-embrionário.

\section{MATERIALEMÉTODOS}

O trabalho foi realizado no Laboratório de Entomologia do Departamento de Zoologia do Centro de Ciências Biológicas da Universidade Federal de Alagoas, no ano de 2000. As coletas foram realizadas em plantas de maracujazeiro, sendo os ovos recolhidos na própria folha ou gavinha logo após a oviposição.

No laboratório, cada ovo foi isolado em tubos de filme fotográfico com $35 \mathrm{~mL}$, sendo colocados juntamente com o fragmento da planta onde estava aderido, sobre papel-filtro umedecido com água destilada. Cada tubo foi devidamente etiquetado e coberto com um pedaço de tecido tipo organdi (com 6,0 cm de lado).

Após a eclosão das larvas, foram feitas limpezas diárias, retirando-se as folhas do dia anterior e substituindo-as por novas. O papel-filtro também era substituído. Todas as observações foram anotadas em planilha: datas de eclosão, ecdises, mortes, pupação e emergência dos adultos.

Uma vez que as lagartas geralmente consumiam toda a exúvia do tórax e abdome, apenas as cápsulas cefálicas foram guardadas para confirmação das ecdises. As duas primeiras foram observadas com a ajuda de estereomicroscópio, pois as cápsulas apresentam um tamanho muito reduzido, confundindose com as fezes, o que dificultava a identificação a olho-nu. As larvas e pupas que morreram durante a condução do experimento foram acondicionadas em frascos contendo álcool $70 \%$.

As lagartas, quando atingiam o quarto ínstar, eram transferidas para gaiolas plásticas (volume interno de aproximadamente $300 \mathrm{~mL}$ ), vedadas com tecido organdi. Na base da gaiola era colocado um guardanapo de papel umedecido e, sobre ele, pedaços de folha de maracujazeiro. Nessas mesmas gaiolas, as lagartas empuparam, especialmente nas paredes superiores, onde permaneceram até a data da emergência dos adultos.

A sexagem foi feita através da observação da extremidade ventral do abdômen. Após a manipulação, os adultos foram montados, juntamente com a exúvia pupal, e incorporados à Coleção Entomológica Prof. José Cordeiro da Silva, pertencente ao Departamento de Zoologia (Centro de Ciências Biológicas da UFAL).

Foram calculadas as estatísticas descritivas determinandose as medidas de tendência central (Média, Moda e Mediana) e as de dispersão (Amplitude, incluindo valores mínimo e máximo, coeficiente de variação e intervalo de confiança da média) com um nível de confiança de 95\% (CRESPO 1995; FERREIRA 2000), indicado para experimentos biológicos dessa natureza. Também foram determinados a assimetria e o grau de achatamento, para confirmar o coeficiente de variação: mesocúrtica $(\mathrm{g}=3)$, platicúrtica $(\mathrm{g}<3)$ e leptocúrtica $(\mathrm{g}>3)$ (CRESPO 1995). Neste trabalho considera-se ínstar como sendo o período inter-ecdisial conforme FINK (1983).

\section{RESULTADOS}

Apesar de ser uma espécie com ampla distribuição (O`ToOLE 1995; Beebe et al. 1960; Holzinger \& Holzinger 1994 apud ANTUNES et al. 2002; Lima \& VeIGA 1993), essa é a primeira vez que Eueides isabella dianasa é registrada para o Estado de Alagoas.

O desenvolvimento pré-imaginal (Tabela I) teve uma duração total variando de 27 a 31 dias, sendo a média de 28,5 dias, com Intervalo de Confiança da Média (IC) de 27,5 a 29,5 dias. Os dados obtidos podem ser considerados homogêneos uma vez que o Coeficiente de Variação (CV) foi de 5,3\%. A distribuição apresentou moda de 27,0 e mediana de 28,5 dias, indicando assimetria positiva. O grau de achatamento foi de 0,1685 indicando que a distribuição é platicúrtica.

O valor absoluto médio obtido está dentro do esperado para a família (26 dias) (BEEBE et al. 1960), e semelhante ao registrado para Agraulis vanillae vanillae (Linnaeus, 1758) (27 dias) e inferior ao de Dione juno juno (Cramer, 1779) onde o ciclo total foi de 45 dias no inverno (GALlo et al. 2002).

O período embrionário apresentou duração absoluta (Tabela I) variando de 3 a 5 dias, sendo a média de 4,3 dias com IC de 3,9 a 4,7 dias. O valor médio representou uma duração relativa de $14,9 \%$ do período pré-imaginal (28,5 dias) (Tabela II). Os dados obtidos podem ser considerados relativamente homogêneos uma vez que o CV foi de $14,6 \%$. A distribuição apresentou moda de 4 dias (igual à mediana), indicando uma assimetria positiva. O grau de achatamento foi de 2,4810, indicando que a distribuição é platicúrtica, tendendo a mesocúrtica.

O valor médio obtido está dentro do esperado para a família (4 dias) (BEEBE et al. 1960), e semelhante ao registrado para $A$. vanillae vanillae (3 dias) e inferior ao de $D$. juno juno com período de incubação de ovos de 7 dias (GAllo et al. 2002). Os ovos de E. isabela dianasa são postos isoladamente da mesma forma que Heliconius erato phyllis (Fabricius, 1775) (OTERO 1985), A. vanillae vanillae, Dryadula phaetusa plaetusa 
Tabela I. Estatísticas descritivas da duração em dias, das fases do desenvolvimento pré-imaginal de Eueides isabella dianasa (Hübner, 1806) (Nymphalidae, Heliconiinae) alimentando-se de folhas de Passiflora edulis Sims. (Passifloraceae) sob condições ambientes de 23,94 $\pm 0,62^{\circ} \mathrm{C}$.

\begin{tabular}{|c|c|c|c|c|c|}
\hline \multirow[b]{2}{*}{ Fase } & \multicolumn{3}{|c|}{ Duração } & \multirow{2}{*}{$\begin{array}{l}\mathrm{CV}^{(2)} \\
(\%)\end{array}$} & \multirow[b]{2}{*}{ Assimetria } \\
\hline & $\begin{array}{l}\text { Média } \pm \\
\mathrm{SM}^{(1)}\end{array}$ & $\begin{array}{c}\text { Moda/ } \\
\text { Mediana }\end{array}$ & $\begin{array}{l}\text { Amplitude Total } \\
\text { (Mínimo-máximo) }\end{array}$ & & \\
\hline Ovo & $4,25 \pm 0,18$ & $4 / 4$ & $2(3-5)$ & 14,62 & $+1,2066$ \\
\hline Larva 1 & $2,75 \pm 0,18$ & $3 / 3$ & $2(2-4)$ & 22,60 & $-1,2066$ \\
\hline Larva 2 & $2,83 \pm 0,17$ & $3 / 3$ & $2(2-4)$ & 20,38 & $-0,8833$ \\
\hline Larva 3 & $3,00 \pm 0,12$ & $3 / 3$ & $2(2-4)$ & 14,21 & 0,0000 \\
\hline Larva 4 & $3,58 \pm 0,19$ & $3 / 3,5$ & $2(3-5)$ & 18,66 & $+0,3590$ \\
\hline Larva 5 - Ativa & $3,58 \pm 0,15$ & $4 / 4$ & $1(3-4)$ & 14,37 & $-2,4469$ \\
\hline - Prepupa & 1 & $1 / 1$ & $0(1-1)$ & 0,00 & - \\
\hline - Total & $4,58 \pm 0,15$ & $5 / 5$ & $1(4-5)$ & 11,23 & $-2,4469$ \\
\hline Larval Ativo & $15,83 \pm 0,34$ & $15 / 15,5$ & $4(15-19)$ & 7,54 & $+0,8296$ \\
\hline Larval Total & $16,83 \pm 0,34$ & $16 / 16,5$ & $4(16-20)$ & 7,09 & $+0,8296$ \\
\hline Pupal & $7,42 \pm 0,15$ & $7 / 7$ & $1(7-8)$ & 6,94 & $+0,2163$ \\
\hline Período de inat. ${ }^{(3)}$ & $8,42 \pm 0,15$ & $8 / 8$ & $1(8-9)$ & 6,12 & $+2,4469$ \\
\hline Pós-embrionário & $24,25 \pm 0,37$ & 23 e $24 / 24$ & $4(23-27)$ & 5,31 & $+0,5823$ \\
\hline Período de inatividade total ${ }^{(4)}$ & $12,67 \pm 0,31$ & $12 / 12$ & $3(11-14)$ & 8,47 & $+1,8731$ \\
\hline Pré-imaginal & $28,50 \pm 0,44$ & $27 / 28,5$ & $4(27-31)$ & 5,29 & $+1,9900$ \\
\hline
\end{tabular}

(Linnaeus [1758]), Dryas julia julia (Fabricius [1775]), Philaethria dido dido (Clerck), Heliconius aliphera aliphera (Godart [1819]), H. isabella isabella (Cramer [1781]), $H$. melpomene euryades Riffarth, $H$. numata ethilla Godart, $H$. erato hydara Hewitson, e diferentemente daquelas que ovipositam pequenos grupos, como $H$. wallacei wallacei Reakir [1866], H. sara thamar (Hübner [1806]) e H. ricini insulata Stichel (BEEBE et al. 1960), e com posturas gregárias: D. juno juno com 70 a 150 ovos (BEEBE et al. 1960; GALlo et al. 2002), Heliconius sara apseudes (Hübner, 1806), com até 200 ovos (OTERo 1986) e Heliconius doris doris (Linnaeus [1771]) (BEEBE et al. 1960).

O período pós-embrionário está representado por cinco ínstares larvais e o pupal, em conformidade com BEEBE et al. (1960), não tido sido observado ínstar extranumerário. A análise dos dados de duração absoluta está especificada na Tabela I, a duração relativa correspondente pode ser observada na Tabela II e a dinâmica no gráfico da Fig. 3. A duração absoluta teve uma variação de 23 a 27 dias, sendo a média de 24,25 dias, superior ao registrado para A. vanillae vanillae [24 dias] (GALLO et al. 2002) e também ao esperado para a família (22 dias) (BEEBE et al. 1960). O IC foi de 23,4 a 25,1 dias. O valor médio representou uma duração relativa de $85,1 \%$ quando comparada ao período pós-embrionário total (28,5 dias). Os dados obtidos podem ser considerados homogêneos uma vez que o coeficiente de variação foi de 5,3\%. A distribuição foi bimodal (23 e 24 dias) com mediana igual a 24 dias, valores menores do que a média, indicando assimetria positiva. O grau de achatamento foi de 1,4051, indicando que a distribuição é platicúrtica.

Primeiro ínstar. A duração absoluta (Tabela I) apresentou uma variação de 2 a 4 dias, sendo a média de 2,75 dias com IC de 2,4 a 3,1 dias. O valor médio representou uma duração relativa (Tabela II) de 11,3\% do desenvolvimento pós-embrionário (24,25\%), o que representa $9,65 \%$ do período pós-embrionário total (28,5 dias). Os dados obtidos podem ser considerados relativamente heterogêneos uma vez que o coeficiente de variação foi de 22,6\%. A distribuição apresentou moda de 3 dias (igual à mediana), indicando uma assimetria negativa. $\mathrm{O}$ grau de achatamento foi de 2,4801, indicando que a distribuição é platicúrtica, tendendo a mesocúrtica.

Segundo ínstar. A duração absoluta (Tabela I) teve uma variação de 2 a 4 dias, sendo a média de 2,8 dias com IC de 2,5 a 3,2 dias. $\mathrm{O}$ valor médio representou uma duração relativa de $11,7 \%$ do desenvolvimento pós-embrionário (24,3\%); essa duração média representa 10,0 \% do período pós-embrionário total (28,5 dias) (Tabela II). Os dados obtidos podem ser considerados relativamente heterogêneos uma vez que o coeficiente de variação foi de $20,4 \%$. A distribuição apresentou moda de 3 dias (igual à mediana), valores maiores que o da média, indicando uma assimetria negativa. O grau de achatamento foi de 2, 2783, indicando que a distribuição é platicúrtica.

Terceiro ínstar. A duração absoluta (Tabela I) teve uma variação de 2 a 4 dias, sendo a média de 3,0 dias com IC de 2,7 a 3,3 dias. $\mathrm{O}$ valor médio representou uma duração relativa de $12,4 \%$ do desenvolvimento pós-embrionário (24,25\%); essa duração média representa $10,5 \%$ do período pós-embrionário total (28,5 dias) (Tabela II). Os dados obtidos podem ser considerados relativamente homogêneos uma vez que o coeficiente de variação foi de 14,2\%. A distribuição apresentou 
Tabela II. Duração absoluta (média) em dias e duração relativa à fase larval e à duração do desenvolvimento pré-imaginal para Eueides isabella dianasa (Hübner, 1806) (Nymphalidae: Heliconiinae) alimentando-se de folhas de Passiflora edulis Sims. (Passifloraceae) sob condições ambientes de $23,94 \pm 0,62^{\circ} \mathrm{C}$.

\begin{tabular}{lccc}
\hline & \multicolumn{3}{c}{ Duração } \\
\cline { 2 - 4 } Fase & $\begin{array}{c}\text { Absoluta } \\
\text { - Média } \\
\text { (dias) }\end{array}$ & $\begin{array}{c}\text { Desenvolvinento Pós- } \\
\text { embrionário }\end{array}$ & $\begin{array}{c}\text { Desenvolvimento } \\
\text { Pré-imaginal }\end{array}$ \\
\cline { 3 - 4 } Ovo & 4,25 & - & 14,91 \\
Larva 1 & 2,75 & 11,34 & 9,65 \\
Larva 2 & 2,83 & 11,68 & 9,94 \\
Larva 3 & 3,00 & 12,37 & 10,53 \\
Larva 4 & 3,58 & 14,77 & 12,57 \\
Larva 5 - Ativa & 3,58 & 14,77 & 12,57 \\
$\quad$ - Prepupa & 1 & 4,12 & 3,51 \\
$\quad$ Total & 4,58 & 18,90 & 16,08 \\
Larval Ativo & 15,83 & 65,29 & 55,56 \\
Larval Total & 16,83 & 69,42 & 59,06 \\
Pupal & 7,42 & 30,58 & 26,02 \\
Período de inatividade* & 8,42 & 34,72 & 29,54 \\
Pós-embrionário & 24,25 & - & 85,09 \\
Período de inatividade total** & 12,67 & - & 44,44 \\
\hline CICLOTOTAL & 28,50 & - & - \\
\hline
\end{tabular}

* Corresponde ao período prepupal + período pupal.

** Corresponde ao período embrionário + período prepupal + período pupal.

moda de 3 dias (igual à mediana e à média), indicando uma curva simétrica. O grau de achatamento foi de 6,0000, indicando que a distribuição é leptocúrtica.

Quarto ínstar. A duração absoluta (Tabela I) teve uma variação de 3 a 5 dias, sendo a média de 3,6 dias com IC de 3,2 a 4,0 dias. $O$ valor médio representou uma duração relativa de $14,8 \%$ do desenvolvimento pós-embrionário $(24,3 \%)$; essa duração média representa $12,6 \%$ do período pós-embrionário total (28,5 dias) (Tabela II). Os dados obtidos podem ser considerados relativamente homogêneos uma vez que o coeficiente de variação foi de $18,7 \%$. A distribuição apresentou moda de 3 dias e mediana 3,5 dias, valores menores do que a média, indicando uma fraca assimetria positiva. $\mathrm{O}$ grau de achatamento foi de 2,4325 , indicando que a distribuição é platicúrtica tendendo a mesocúrtica.

Quinto ínstar. O quinto ínstar apresentou duas fases distintas denominadas de fase ativa e prepupa. A fase ativa (Fig. 1) apresentou uma duração absoluta (Tabela I) variando de 3 a 4 dias, sendo a média de 3,6 dias com IC de 3,3 a 3,9 dias. $\mathrm{O}$ valor médio representou uma duração relativa (Tabela II) de $14,8 \%$ do desenvolvimento pós-embrionário (24,25\%); essa duração média representa $12,6 \%$ do período pós-embrionário total (28,5 dias) (Tabela II). Os dados obtidos podem ser considerados relativamente homogêneos uma vez que o coeficiente de variação foi $14,4 \%$. A distribuição apresentou moda e mediana igual a 4 dias, valor superior ao da média, indicando uma assimetria negativa. O coeficiente de curtose foi de 1,1053, caracterizando a distribuição como platicúrtica.

O período prepupal não apresentou variação, uma vez que em todos os espécimes a duração foi de um dia.

A duração total do quinto ínstar (Tabela I) teve uma variação de 4 a 5 dias, sendo a média de 4,6 dias com IC de 4,3 a 4,9 dias. O valor médio representou uma duração relativa de $18,9 \%$ do desenvolvimento pós-embrionário (24,3\%); essa duração média representa $16,1 \%$ do período pós-embrionário total (28,5 dias) (Tabela II). Os dados obtidos podem ser considerados relativamente homogêneos uma vez que o coeficiente de variação foi de $11,2 \%$. A distribuição apresentou moda de 5 dias (igual à mediana), valores maiores do que a média, indicando uma assimetria negativa. $\mathrm{O}$ grau de achatamento foi de 1,1053, indicando que a distribuição é platicúrtica.

Período larval ativo. A duração absoluta (Tabela I) teve uma variação de 15 a 19 dias, sendo a média de 15,8 dias com IC de 15,1 a 16,6 dias. O valor médio representou uma duração relativa de $65,3 \%$ do desenvolvimento pós-embrionário $(24,25 \%)$; essa duração média representa $55,6 \%$ do período pós-embrionário total (28,5 dias) (Tabela II).Os dados obtidos podem ser considerados homogêneos uma vez que o coeficiente de variação foi de 7,5\%. A distribuição apresentou moda de 15 dias e mediana de 15,5 dias, valores menores do que a média, indicando uma fraca assimetria positiva. $\mathrm{O}$ grau de achatamento foi de 5,1682, indicando que a distribuição é leptocúrtica.

Período larval total. A duração absoluta (Tabela I) teve uma variação de 16 a 20 dias, sendo a média de 16,8 dias com IC de 16,1 a 17,6 dias. O valor médio representou uma duração relativa de $69,4 \%$ do desenvolvimento pós-embrionário (24,3\%); essa duração média representa $59,1 \%$ do período pósembrionário total (28,5 dias) (Tabela II). Os dados obtidos podem 

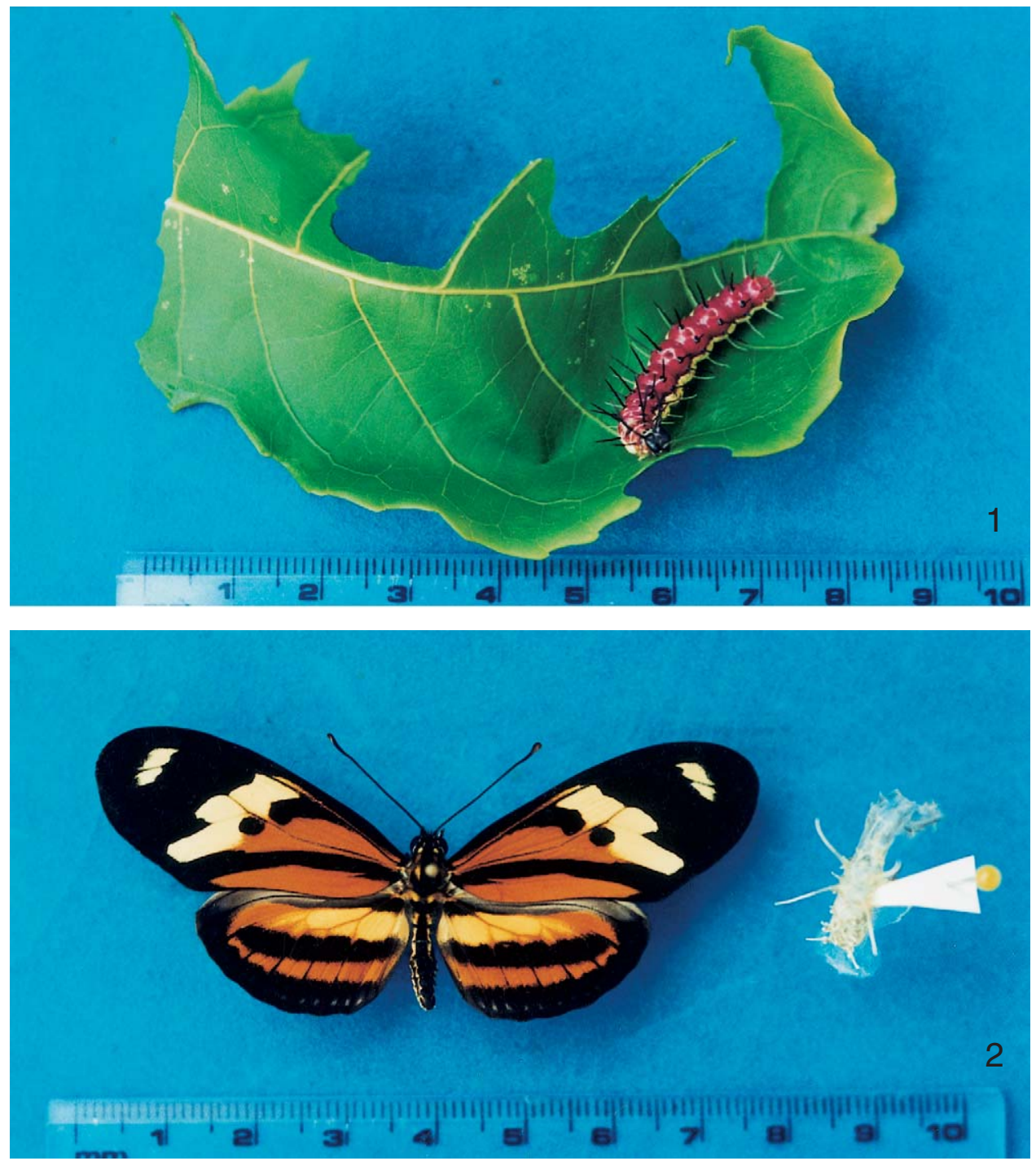

Figs. 1-2. Eueides isabella dianasa (Hübner, 1806) (Nymphalidae, Heliconiinae). 1, larva no quinto ínstar alimentando-se de folhas de Passiflora edulis L. (Passifloraceae) sob condições ambientes de $23,94 \pm 0,62^{\circ} \mathrm{C} ; \mathbf{2}$, adulto em vista dorsal com exúvia pupal à direita. (Fotos de Iracilda Maria de Moura Lima).

ser considerados homogêneos uma vez que o coeficiente de variação foi de $7,1 \%$. A distribuição apresentou moda de 16 dias e mediana de 16,5 dias, valores menores do que a média, indicando uma fraca assimetria positiva. O grau de achatamento foi de 5,1679, indicando que a distribuição é leptocúrtica.

O valor médio obtido está dentro do esperado para a família (no mínimo 13 dais), e é semelhante ao registrado para $A$. vanillae vanillae (17 dias) e inferior ao de $D$. juno juno com período larval de 26 dias (GALlo et al. 2002).

Período Pupal. A duração absoluta (Tabela I) da fase de pupa teve uma variação de 7 a 8 dias, sendo a média de 7,4 dias, valor inferior ao registrado para $D$. juno juno (12 dias) e também ao esperado para a família (9 a 10 dias) (BEEBE et al. 1960), mas semelhante ao de A. vanillae vanillae (7 dias) (GALlo et al. 2002). O IC foi de 7,1 a 7,7 dias. O valor médio representou uma duração relativa de $30,6 \%$ do desenvolvimento pós- embrionário (24,3\%); essa duração média representa 26,0\% do período pós-embrionário total (28,5 dias) (Tabela II). Os dados obtidos podem ser considerados relativamente homogêneos uma vez que o coeficiente de variação foi de 6,9\%. A distribuição apresentou moda de 7 dias (igual à mediana), valores menores do que a média, indicando assimetria positiva. O grau de achatamento foi de 1,1053 , indicando que a distribuição é platicúrtica.

O período de inatividade dentro do desenvolvimento pósembrionário compreende a soma da duração do período prepupal (período inativo do quinto ínstar larval) e o pupal. A duração absoluta (Tabela I) teve uma variação de 8 a 9 dias, sendo a média de 8,4 dias com IC de 8,1 a 8,7 dias. O valor médio representou uma duração relativa de $34,7 \%$ do desenvolvimento pós-embrionário (29,5\%); essa duração média representa $26,0 \%$ do período pós-embrionário total (28,5 dias) 
Tabela III. Viabilidade de ovos e sobrevivência, em cada um dos períodos do desenvolvimento pós-embrionário de Eueides isabella dianasa (Hübner, 1806) (Nymphalidae, Heliconünae) alimentando-se de folhas de Passiflora edulis Sims. (Passifloraceae) sob condições ambientes de $25,51^{\circ} \mathrm{C}$.

\begin{tabular}{|c|c|c|c|c|c|}
\hline \multirow{2}{*}{$\begin{array}{l}\text { Período do } \\
\text { Desenvolvimento }\end{array}$} & \multirow{2}{*}{$\begin{array}{l}\text { Médias } \\
\text { acumuladas }\end{array}$} & \multicolumn{2}{|c|}{ Unidades de Prova (Número) } & \multicolumn{2}{|c|}{ Sobrevivência (\%) } \\
\hline & & Inicial & Final & No Estádio & $\begin{array}{l}\text { Acumulada (em relação } \\
\text { ao número de neonatos) }\end{array}$ \\
\hline $\begin{array}{l}\text { Embrionário } \\
\text { (Viabilidade) }\end{array}$ & 0,00 & 40 & 38 & 95,00 & - \\
\hline $\mathrm{L} 1$ & 2,75 & 38 & 34 & 89,47 & 89,47 \\
\hline $\mathrm{L} 2$ & 5,58 & 34 & 30 & 88,23 & 78,95 \\
\hline $\mathrm{L} 3$ & 8,58 & 30 & 29 & 96,67 & 76,31 \\
\hline L4 & 12,16 & 29 & 27 & 93,10 & 71,05 \\
\hline L5 & 16,74 & 27 & 17 & 62,96 & 44,74 \\
\hline $\begin{array}{l}\text { Larval total } \\
\text { Pupal: }\end{array}$ & & 38 & 17 & 44,74 & 44,74 \\
\hline Morte no estádio & & 17 & 12 & 70,59 & 31,57 \\
\hline Falha de emergência & & 12 & 11 & 91,67 & 28,95 \\
\hline Total & 24,25 & 17 & 11 & 64,71 & 28,95 \\
\hline $\begin{array}{l}\text { Pós-embrionário } \\
\text { (larva neonata a adulto) }\end{array}$ & & 38 & 11 & 28,95 & - \\
\hline Total (ovo a adulto) & & 40 & 11 & 27,50 & - \\
\hline
\end{tabular}

(Tabela II). Os dados obtidos podem ser considerados homogêneos uma vez que o coeficiente de variação foi de $6,1 \%$. A distribuição apresentou moda de 8 dias (igual à mediana), valores menores do que a média, indicando assimetria positiva. O grau de achatamento foi de 0,1325, indicando que a distribuição é platicúrtica.

A duração absoluta do período de inatividade dentro do desenvolvimento pré-imaginal (Tabela I) teve uma variação de 11 a 14 dias, sendo a média de 12,7 dias com IC de 12,0 a 13,4 dias. $\mathrm{O}$ valor médio representou uma duração relativa 44,4\% quando comparada ao período pós-embrionário total (28,5 dias)

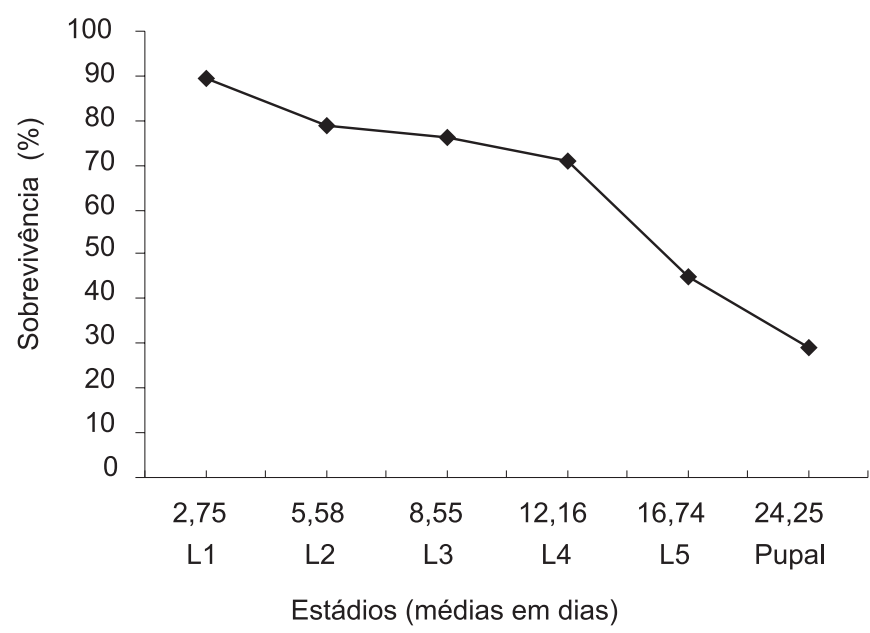

Fig. 3. Duração relativa dos ínstares do desenvolvimento desenvolvimento pré-imaginal de Eueides isabella dianasa (Hübner, 1806) (Nymphalidae, Heliconiinae) alimentando-se de folhas de Passiflora edulis Sims. (Passifloraceae) sob condições ambientes de $25,51^{\circ} \mathrm{C}$.
(Tabela II). Os dados obtidos podem ser considerados homogêneos uma vez que o coeficiente de variação foi de $8,5 \%$. A distribuição apresentou moda de 12 dias (igual à mediana), valor menor que o da média, indicando assimetria positiva. $\mathrm{O}$ grau de achatamento foi de 1,6091, indicando que a distribuição é leptocúrtica.

O acompanhamento das perdas de unidades de prova ao longo do bioensaio, pode ser observado na Tabela III. Dos 40 ovos coletados no campo, com data de postura não conhecida, apenas dois não eclodiram, o que representa uma viabilidade de $95 \%$. A partir daí, foi analisada a sobrevivência com base no registro das mortes.

Em todos os ínstares foram detectadas baixas no número de unidades de prova. A fase onde foram observadas as maiores

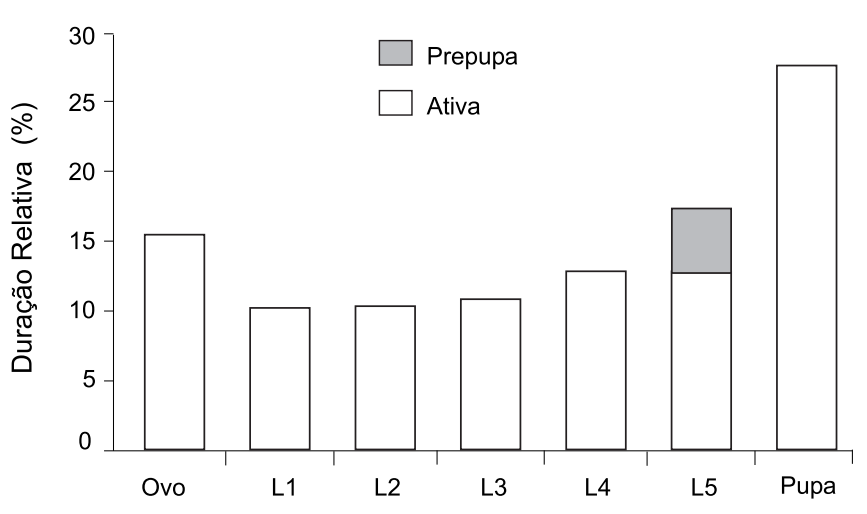

Fig. 4. Dinâmica da sobrevivência ao longo do desenvolvimento pósembrionário (24,25 dias) de Eueides isabella dianasa (Hübner, 1806) (Nymphalidae,Heliconiinae) alimentando-se de folhas de Passiflora edulis Sims. (Passifloraceae) sob condições ambientes de $25,51^{\circ} \mathrm{C}$. 
perdas foi no quinto ínstar (63,0\%), seguido do período pupa $(64,3 \%)$ com mortes no período e no momento da emergência do adulto. A sobrevivência nos outros períodos variou de 88,2 a 93,0\% e a sobrevivência acumulada, considerando as larvas neonatas, foi baixa, isto é, das larvas neonatas, apenas $31,6 \%$ conseguiram atingir o estádio adulto.

Observando-se o total inicial de ovos (40), foram obtidos apenas $27,5 \%$ de adultos viáveis. Na fase de pupa foram considerados dois tipos de morte: o que se deu no estádio, sem conseguir completá-lo $(70,6 \%)$ e no momento da ecdise pupal, com uma falha de emergência ( $91,7 \%$ de sobrevivência).

Agradecimentos. Os autores agradecem ao Dr. Olaf H. H. Mielke (Universidade Federal do Paraná) pela identificação de Eueides isabella dianasa (Hübner 1806) e à Bióloga Rosângela Pereira de Lyra-Lemos do Herbário MAC, do Instituto do Meio Ambiente do Estado de Alagoas, pela identificação da planta-hospedeira.

\section{REFERÊNCIAS}

Antunes, F. F.; A. O. Menezes JR.; M. Tavares \& G. R. P. Moreira. 2002. Ultraestrutura tegumentar externa dos estágios imaturos de Heliconiíneos neotropicais. I. Eueides isabella dianasa (Hübner, 1906). Revista Brasileira de Entomologia 46(4): 601-610.

Beebe, W.; J. Crane \& H. Fleming. 1960. A comparasion of eggs, larvae and pupae in fourteen species of Heliconiinae butterflies from Trinidad, W. I. Zoologica 45(8): 111-154.

Brown JR., K. S. 1981. The biology of Heliconius and related genera. Annual Review of Entomology 26: 427-456.

Picanço, M.; A. H. R. Gonring; \& I. R. Oliveira. 2001. Manejo Integrado de Pragas, p. 189-242. In: Bruckner, C. H. \& M. C. Picanço (ed.).
Maracujá: tecnologia de produção, pós-colheita, agroindústria, mercado. Porto Alegre, Cinco continentes, 472 p. Carrera, M. 1989. Entomologia para você. $7^{a}$ ed. São Paulo, Nobel, $135 \mathrm{p}$.

Crespo, A. A. 1995. Estatística Fácil. São Paulo, Saraiva, 224 p.

Ferreira, P. V. 2000. Estatística experimental aplicada à agronomia. Maceió, Editora da Universidade Federal de Alagoas 419 p.

Figueiredo, O. S. DE. 2000. Criação de borboletas. Viçosa, Centro de Produções Técnicas, 78 p. (Série Pequenas Criações, Manual n 281).

Fink, T. J. 1983. A Further Note on the Use of the Terms Instar, Stadium, and Stage. Annals of the Entomological Society of América 76(3): 316-318.

Gallo, D.; O. Nakano; S. Silveira-Neto; R. P. L. Carvalho; G. C. De Batista; E. Berti-Filho; J. R. P. Parra; R. A. Zucchi; S. B. Alves \& J. D. Vendramim. 2002. Manual de entomologia agrícola. Piracicaba, FEALQ, $920 \mathrm{p}$.

Holzinger, H. \& R. Holzinger. 1994. Heliconius and related genna: Lepidoptera Nymphalidae. The genera Eueides, Neruda and Heliconius. Venette, Sciences Natural., 328 p.

Lima, M. DE F. C. \& A. F. DE S. L. Veiga. 1993. Ocorrência de D. juno juno (Cr.), A. vanillae maculosa S. e Eueides isabella dianasa (Hüb.) (Lepidoptera: Nymphalidae) em Pernambuco. Anais da Sociedade Entomológica do Brasil 24(3): 631-633.

Mugrabi-Oliveira, E. \& G. R. O. Moreira. 1996. Conspecific mimics and low host plant availability reduce egg laying by Heliconius erato phyllis (Fabricius) (Lepidoptera, Nymphalidae). Revista Brasileira de Zoologia 13(4): 929-937.

O'Toole, C. 1995. Defense in a hostile world, p. 122-149. In: C. O'Toole, 1995. The Alien empire: an exploration of the lives of insects. Oxfordshire, Andromeda Oxdford, $224 \mathrm{p}$

Otero, L. S. 1986. Borboletas: livro do naturalista. Rio de Janeiro, Fundação de Assistência ao Estudante, 112 p.

Silva, A. G. D’A.; C. R. Gonçalves; D. M. Galvão; A. J. L. GonçAlves; J. Gomes; M. do N. Silva \& L. DE Simoni. 1968. Quarto Catálogo dos insetos que vivem nas plantas do Brasil seus parasitos e predadores: insetos, hospedeiros e inimigos naturais. Parte 2: Tomo 1. Rio de Janeiro, Ministério da Agricultura, 622 p. 